\title{
Extremely delayed renal cell carcinoma metastasis mimicking convexity meningioma
}

\author{
G. Bademci; O. Bozdogan*; F. Berdan and C. Evliyaoglu
}

Departments of Neurosurgery and Pathology. Faculty of Medicine. University of Kirikkale. Turkey.

\section{Summary}

Cerebral extra-axial metastasis mimicking meningioma which satisfy several criteria for a diagnosis of meningioma, but which have proved instead to be metastatic carcinoma and extremely delayed cerebral metastasis from renal cell carcinoma form the focus of the presentation.

68-year-old-woman who had been operated for renal cell carcinoma 20 years previously is presented with new symptoms of intracranial mass. A large extraaxial mass of the convexity which destroyed calvarium and dura was excised with Simpson Grade I removal, revealed metastatic carcinoma.

Imaging characteristics can not always discern between meningioma and metastatic tumours. A meticulous clinical evaluation and histopathological diagnosis is essential in patients with intracranial mass even they resemble both primary and metastatic tumours.

KEY WORDS: Meningioma. Convexity. Renal cell carcinoma. Metastasis

Metástasis muy tardía de carcinoma renal, simulando un meningioma de la convexidad

\section{Resumen}

Se presenta un caso de metástasis craneal extra-axial, que satisface varios criterios para el diagnóstico de meningioma, en el cual se demostró que se trataba de la metástasis tardía de un carcinoma renal.

Una paciente de 61 años, que había sido operada de un carcinoma renal 20 años antes, se presentó con síntomas de un tumor cerebral. Se extirpó un gran tumor extra-axial de la convexidad, que destruía la bóveda craneal y la duramadre, (Simpson grado I), pero que reveló se trataba de una metástasis.

Las imágenes de estas característica no siempre

Recibido: 11-06-07. Aceptado: 20-02-08 pueden discernir entre un meningioma y una metástasis. Es esencial realizar una meticulosa valoración clínica y un diagnóstico histopatológico en pacientes con tumores intracraneales, aunque parezcan tumores metastáticos.

Introduction

Cerebral metastases are the most frequent brain tumours in adults. Cerebral metastases are generally intraaxial tumours, whereas extra-axial masses mimicking meningioma are extremely rare ${ }^{1,5}$. The pathophysiology of dural metastasis of the tumours is still subject of debate. Two mechanisms have been put forward involving venous and arterial dissemination. Because of the prognostic relevance in discriminating meningiomas and metastatic tumours, differential diagnosis is essential in the isolated extra-axial tumour management even when a meningioma is suspected.

\section{Case report}

68-year-old woman admitted to the neurosurgery department of University of Kirikkale, Faculty of Medicine complaining new onset of headache, speech disturbance, progressive right hemiparesis and confusion. History of the patient revealed a nephrectomy procedure which had been performed 20 years previously due to a neoplastic aetiology. Cranial CT scan revealed heterogenous highdensity, well-demarcated enhancing extra-axial mass of the left temporoparietal convexity with a partially calcified dural basis and extensive calvarial defect suggestive meningioma (Figure I and II). Magnetic Resonance Imaging (MRI) could not be performed because of the presence of MRI-incompatible knee prothesis of the patient. A craniotomy excessively surrounding the defective bony area was performed to remove the large mass which was extensively attached to the dura mater. After the tumour was removed totally, the duraplasty and cranioplasty procedures were performed to reconstruct the large dura and bony defects. The patient recovered from the preoperative 


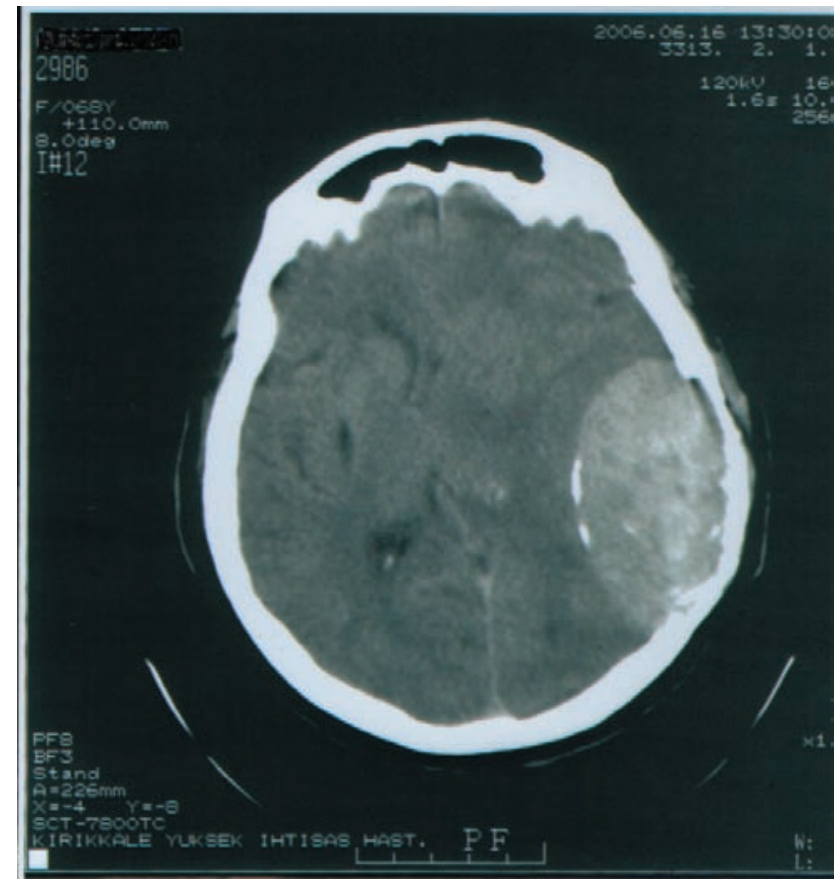

Figure I. Axial CT scan showing left temporoparietal, welldemarcated, partially calcified and heteregenous large mass invaded to the cranium suggestive meningioma.

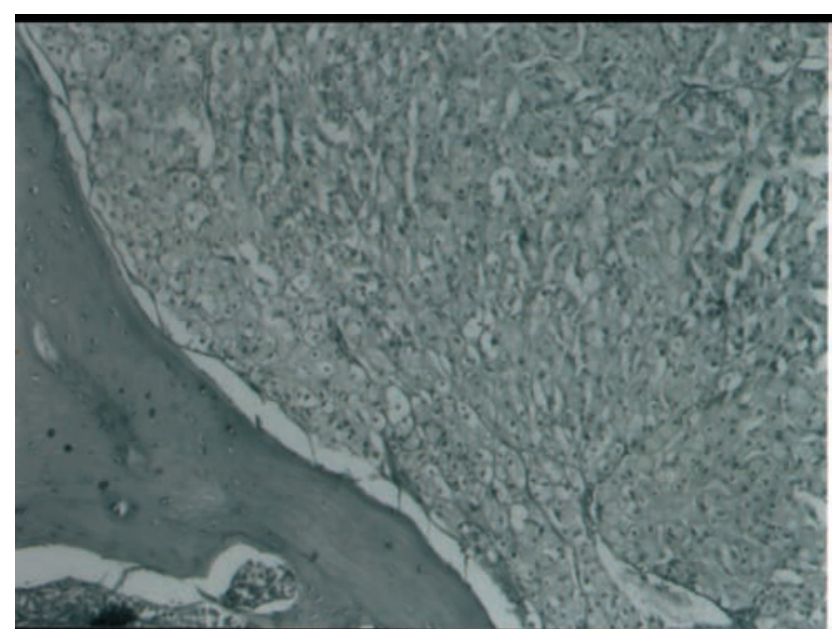

Figure III. Histopathologic appearance of cranial metastatic carcinoma invaded to the bone. (X20 magnification, Hematoxylin Eosin staining).

neurologic deficits with excellent results. Operative features indicated a dura-based tumour which was thought to be a meningioma. However, the pathological examination of the meningiomatous mass revealed extensively infiltrated dura and calvarium with deposits of solid mass indicating metastatic carcinoma (Figure III). Tumour cells had invaded all the layers of the calvarium and dura. The histopathologic examination showed a malignant carci-

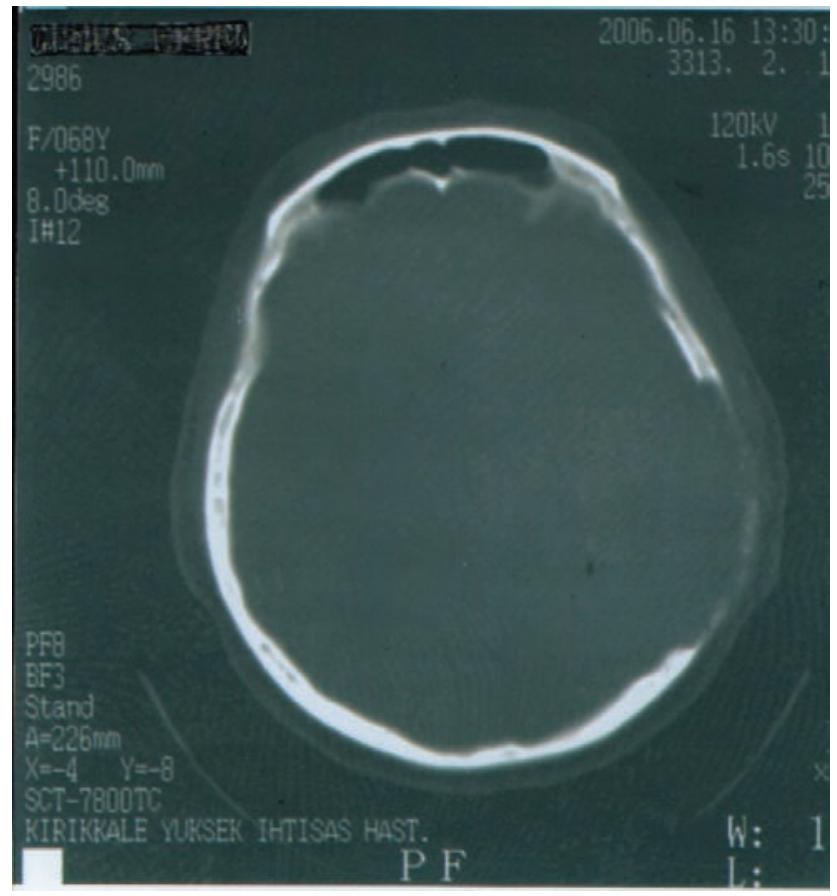

Figure II. Axial CT scan bony picture showing extensive cranial bony defect due to metastatic invasion.

noma with necrotic foci and mitotic figures. Immunohistochemical examination of the mass, dura and bone after excision showed metastatic carcinoma immunopositive for pancytokeratin, EMA and S-100. Weak staining was seen for vimentin while CD68 and CD34 immunostatin were negative. Retrospective investigation of pathologic records of the patient revealed that primary focus of carcinoma was within the kidney. In the postoperative examination, multiple micronodular lesions were found in the lung by thorax CT indicative for lung metastasis. No recurrence was observed during 4 months follow-up period after cranial surgery. Then, the patient was referred to the oncology department for additional therapy protocols.

\section{Discussion}

The extra-axial, dura-based location of metastatic tumours may cause radiologically diagnostic confusion with a meningioma. Entities mostly associated with meningiomas such as calcified nature, dura-based location, dural tail, skull erosion, well-demarcated contour and heterogenous enhancement can make preoperative differentiation between metastatic brain tumour and meningioma difficult ${ }^{10}$. Radiologic features are not patognomonic for meningioma and neuroimaging appearance of metastatic brain tumours may be very similar to meningioma. Furthermore, a number of neoplastic and non-neoplastic entities have been reported that radiologically and clinically mimicking meningioma ${ }^{4}$. 
Metastatic brain tumours can also be calcified and should be considered in the differential diagnosis of calcified intracranial lesions. Some authors consider the dural tail sign nearly diagnostic of meningioma, although it is commonly accepted that the tail sign appears to be highly suggestive but not specific for meningioma ${ }^{3,9}$.

Contrastly, a previous report revealed a case of malignant meningioma mimicking a solitary brain metastasis in a patient with renal cell carcinoma ${ }^{11}$. Although these misleading situations are rarely presented, it is essential that a clinical diagnosis requires circumspection and both primary and metastatic tumours should be considered when a solitary brain lesion is encountered.

Dural metastases are mostly indistinguishable from meningiomas using conventional radiologic modalities like $\mathrm{CT}$ and MRI. Kremer et al. reported that relative cerebral blood volume (rCBV) mapping can provide additional information by demonstrating a low rCBV which may suggest the diagnosis of metastasis ${ }^{7}$. As radiologic aspects are not specific and confusing, extra-axial mass should be carefully investigated in patients with a tumour simulating meningioma. A thorough detailed clinical evaluation may reveal likely diagnostic possibilities. We emphasize the importance of "suspecting" of a metastatic disease in all patients with solitary dural mass simulating meningioma.

Metastatic disease should be considered in all patients with prior resection of renal cell carcinoma who experienced the onset of neurological disease even after a prolonged disease-free interval rather than a coincidence of primary brain tumor like meningioma. Solitary brain metastases of renal cell carcinoma with a latency period of more than 20 years after nephrectomy have been extremely rare in the literature ${ }^{2}$. The long interval of latency may be attributed to the slow growing characteristic of renal cell carcinoma and the fact that renal cell carcinoma is under the influence of host immunity. Up to our knowledge this is the second report of a case with renal cell carcinoma describing the first solitary metastatic brain lesion which occurred 20 years after nephrectomy ${ }^{2}$.

Review of the literature revealed that two cases were reported with metastatic renal cell carcinoma mimicking intraventricular meningioma ${ }^{6,8}$. Present case is also unique as a mass simulating a large convexity meningioma with extensive dural and calvarial involvement requiring Simpson Grade 1 removal.

\section{Conclusion}

Careful vigilance in patients with a history of cancer and presenting with new symptoms or imaging evidence of dura-based lesions is critically important to provide timely intervention even after prolonged disease-free interval. The neuroradiological features of metastatic brain tumours may thus closely resemble of meningioma. Radiological and clinical aspects that warrant the diagnosis of meningioma should be considered "only neoplastic" until histologically proven otherwise. The definitive diagnosis of a meningioma should be established only after the histopathological report has been analyzed. Also we conclude that the patients undergone cancer surgery should always be followed neurologically and radiologically more than 10 years after the initial treatment.

\section{References}

1. Ahn, J.Y., Kim, N.K., Oh, D., Ahn, H.J.: Thymic carcinoma with brain metastasis mimicking meningioma. J Neurooncol 2002; 58: 193-199.

2. Cimatti, M., Salvati, M., Caroli, E., Frati, A., Brogna, C., Gagliardi, F.M.: Extremely delayed cerebral metastasis from renal carcinoma: report of four cases and critical analysis of the literature. Tumori 2004; 90: 342-344.

3. Gupta, S., Gupta, R.K., Banerjee, P., Gujral, R.B.: Problems with the dural tail. Neuroradiology 1993; 35: 541-542.

4. Johnson, M.D., Powell, S.Z., Boyer, P.J., Weil, R.J., Moots, P.L.: Dural lesions mimicking meningiomas. Hum Pathol 2002; 33: 1211-1226.

5. Khalfallah, M., Roche, P.H., Figarrela, D., Malca, S., Pellet, W.: Dural metastases mimicking meningioma. Report of a case. Neurochirurgie 1999; 45: 250-254.

6. Killebrew, K., Krigman, M., Mahaley, M.S., Scatliff, J.H.: Metastatic renal cell carcinoma mimicking a meningioma. Neurosurgery 1983; 13: 430-434.

7. Kremer, S., Grand, S., Remy, C., Pasquier, B., Benabid, A.L., Bracard, S., Le Bas, J.F.: Contribution of dynamic contrast MR imaging to the differentiation between dural metastasis and meningioma. Neuroradiology 2004; 46: 642-648.

8. Quinones-Hinojosa, A., Chang, E.F., Khan, S.A., Lawton, M.T., McDermott MW.: Renal cell carcinoma metastatic to the choroid mimicking intraventricular meningioma. Can J Neurol Sci 2004; 31: 115-120.

9. Senegor, M.: Prominent meningeal tail sign in a patient with a metastatic tumor. Neurosurgery 1991; 29: 294-296.

10. Tagle, P., Villanueva, P., Torrealba, G., Huete, I.: Intracranial metastasis or meningioma? An uncommon clinical diagnostic dilemma. Surg Neurol 2002; 58: 241-245.

11. Yashi, M., Sasaki, M., Ono, T.: Ring-enhanced malignant meningioma mimicking a brain metastasis from a renal cell carcinoma. Urol Int 2003; 70: 80-82.

Bademci, G.; Bozdogan, O.; Berdan, F.; Evliyaoglu, C.: Extremely delayed renal cell carcinoma metastasis mimicking convexity meningioma. Neurocirugía 2008; 19: 562-564.

Correspondence: Gulsah Bademci, MD. Buketkent Mh. Iller Sitesi 9/9 06530. Cayyolu/Ankara/Turkey. 